\title{
Differential Effects of NMDA and AMPA Glutamate Receptors on Functional Magnetic Resonance Imaging Signals and Evoked Neuronal Activity during Forepaw Stimulation of the Rat
}

\author{
Willy Gsell, ${ }^{1,2,3 *}$ Michael Burke, ${ }^{1,4}$ Dirk Wiedermann, ${ }^{1}$ Gilles Bonvento, ${ }^{5}$ Afonso C. Silva, ${ }^{6}$ François Dauphin, ${ }^{2,7}$ \\ Christian Bührle, ${ }^{1,8}$ Mathias Hoehn, ${ }^{1}$ and Wolfram Schwindt ${ }^{1,9 *}$ \\ ${ }^{1}$ Max Planck Institute for Neurological Research, 50931 Cologne, Germany, ${ }^{2}$ Centre National de la Recherche Scientifique, Unité Mixte de Recherche 6551, \\ University of Caen, 14032 Caen, France, ${ }^{37 T}$ MR Facility, Wellcome Surgical Institute, University of Glasgow, Glasgow 6G1 1QH, United Kingdom, ${ }^{4}$ Faculty \\ of Psychology, Section for Experimental and Biological Psychology, Universität Marburg, 35032 Marburg, Germany, ${ }^{5}$ Commissariat à l'Energie Atomique, \\ Unité de Recherche Associée, Centre National de la Recherche Scientifique 2210, Service Hospitalier Frédéric Joliot, 91401 Orsay, France, ${ }^{6}$ Laboratory of \\ Functional and Molecular Imaging, National Institute of Neurological Disorders and Stroke, Bethesda, Maryland 20892, 7Pharmacology, Centre d'Etudes et \\ de Recherche sur le Médicament de Normandie, University of Caen, 14032 Caen, France, ${ }^{8}$ Department of Stereotactic and Functional Neurosurgery, University of \\ Cologne, 50923 Cologne, Germany, and ${ }^{9}$ Department of Clinical Radiology, University Hospital Münster, 48129 Münster, Germany
}

\begin{abstract}
Most of the currently used methods for functional brain imaging do not visualize neuronal activity directly but rather rely on the elicited hemodynamic and/or metabolic responses. Glutamate, the major excitatory neurotransmitter, plays an important role in the neurovascular/neurometabolic coupling, but the specific mechanisms are still poorly understood. To investigate the role of the two major ionotropic glutamate receptors [NMDA receptors (NMDA-Rs) and AMPA receptors (AMPA-Rs)] for the generation of functional magnetic resonance imaging (fMRI) signals, we used fMRI [measurements of blood oxygenation level-dependent (BOLD), perfusion-weighted imaging (PWI), and cerebral blood volume (CBV)] together with recordings of somatosensory evoked potentials (SEPs) during electrical forepaw stimulation in the $\alpha$-chloralose anesthetized rat. Intravenous injection of the NMDA-R antagonist MK-801 [(+)-5-methyl-10,11dihydro-5H-dibenzo [a,d] cyclohepten-5,10-imine maleate] $\left(0.06 \mathrm{mg} / \mathrm{kg}\right.$ plus $\left.3.6 \mu \mathrm{g} \cdot \mathrm{kg}^{-1} \cdot \mathrm{h}^{-1}\right)$ significantly decreased BOLD $(-51 \pm$ $19 \% ; n=5)$ and PWI $(-57 \pm 26 \% ; n=5)$ responses but reduced the SEPs only mildly (approximately $-10 \%)$. Systemic application of the AMPA-R antagonist GYKI-53655 [1-(4-aminophenyl)-3-methylcarbamyl-4-methyl7,8-methylenedioxy-3,4-dihydro-5H-2,3benzodiazepine] significantly decreased both the hemodynamic response (BOLD, $-49 \pm 13$ and $-65 \pm 15 \%$; PWI, $-22 \pm 48$ and $-68 \pm$ $4 \%$ for 5 and $7 \mathrm{mg} / \mathrm{kg}$, i.v., respectively; CBV, $-80 \pm 7 \%$ for $7 \mathrm{mg} / \mathrm{kg} ; n=4$ ) and the SEPs (up to $-60 \%$ ). These data indicate that the interaction of glutamate with its postsynaptic and/or glial receptors is necessary for the generation of blood flow and BOLD responses and illustrate the differential role of NMDA-Rs and AMPA-Rs in the signaling chain leading from increased neuronal activity to the hemodynamic response in the somatosensory cortex.
\end{abstract}

Key words: glutamate; AMPA receptors; NMDA receptors; functional magnetic resonance imaging; evoked potentials; somatosensory cortex; rat

\section{Introduction}

Non-invasive neuroimaging techniques such as positron emission tomography and functional magnetic resonance imaging

\footnotetext{
Received June 3, 2004; revised June 27, 2006; accepted June 28, 2006.

This work was supported by grants from PROCOPE (Programme de Coopération Scientifique; French-German Binational Cooperation Program) (G.B., M.H.) and in part by the Intramural Research Program of the National Institutes of Health-National Institute of Neurological Disorders and Stroke (A.C.S.). We are grateful to Dr. Claire Corot (Guerbet, Paris, France) for the donation of Sinerem.

${ }^{*}$ W.G. and W.S. contributed equally to this work.

Correspondence should be addressed to Dr. Wolfram Schwindt, Department of Clinical Radiology, University Hospital Münster, D-48129 Münster, Germany. E-mail: wschwindt@uni-muenster.de. DOI:10.1523/JNEUROSCI.4615-05.2006

Copyright $\odot 2006$ Society for Neuroscience $\quad 0270-6474 / 06 / 268409-08 \$ 15.00 / 0$
}

(fMRI) provide a unique view of the brain at work (Raichle, 1998). These methods rely on the complex relationship between neuronal activity, energy metabolism, and cerebral blood flow (CBF) to map brain function. The exact neurochemical signaling processes involved in controlling the cerebrometabolic and the cerebrovascular couplings remain unclear (Attwell and Iadecola, 2002; Bonvento et al., 2002; Logothetis and Wandell, 2004). Neuronal activity requires energy, which is provided almost exclusively by oxidation of glucose (Siesjo, 1978). Because the brain has very little energy reserves, a continuous supply of glucose and oxygen is mandatory to maintain neuronal activity. This supply is controlled locally and dynamically to meet the increased energetic demands during functional activation. Approximately $90 \%$ 
of the neuronal activity in the cerebral cortex is mediated by glutamate as the major excitatory amino acid (Nicholls, 1992; De Felipe et al., 1997; Attwell and Laughlin, 2001). Glutamate release may trigger vascular as well as metabolic responses via distinct coupling mechanisms (Bonvento et al., 2002).

The metabolic response, on the one hand, is probably mediated by glial transport of glutamate and its recycling through mechanisms involving changes in intracellular $\mathrm{Na}^{+}$concentration (Pellerin and Magistretti, 1994; Chatton et al., 2000; Bernardinelli et al., 2004). This hypothesis has received in vivo experimental support from both magnetic resonance spectroscopy studies (for review, see Rothman et al., 2003) and recent findings that increases in cerebral glucose utilization after somatosensory or visual stimulation are markedly reduced in knock-out mice deficient for each of the two glial glutamate transporters GLAST and GLT-1 (Voutsinos-Porche et al., 2003a,b; Herard et al., 2005).

The hemodynamic response, on the other hand, seems to be governed by other mechanisms in addition to those controlling the metabolic response. Although there is a tight correlation between changes of local field potentials and the hemodynamic response (Lauritzen and Gold, 2003; Logothetis and Pfeuffer, 2004), the precise mechanisms and in particular the contribution of the glutamatergic transmitter system are not yet well characterized (Bonvento et al., 2002; Iadecola, 2004).

Glutamatergic neuroexcitation is mediated through ligandgated ion channels (ionotropic receptors) and G-proteincoupled (metabotropic) glutamate receptors (Ozawa et al., 1998). The ionotropic glutamate receptors are subdivided into three major groups [AMPA (AMPA-Rs), NMDA (NMDA-Rs), and kainic acid receptors]. AMPA-Rs primarily function as $\mathrm{Na}^{+}$ channels, with rapid activation and deactivation kinetics characterizing this class of receptors as mediators of fast excitatory neurotransmission. NMDA-Rs, conversely, preferentially work as $\mathrm{Ca}^{2+}$ channels, with much slower kinetics than AMPA-Rs.

The aim of the present study was to investigate the role of NMDA-Rs and AMPA-Rs in mediating the hemodynamic response to somatosensory stimulation. For this purpose, we combined fMRI and recording of somatosensory evoked potentials (SEPs) in the $\alpha$-chloralose anesthetized rat, to simultaneously assess the hemodynamic response and the neuronal activity, respectively, before and after administration of specific NMDA-R and AMPA-R antagonists, MK-801 [(+)-5-methyl-10,11dihydro-5H-dibenzo $[\mathrm{a}, \mathrm{d}]$ cyclohepten-5,10-imine maleate] and GYKI-53655 [1-(4-aminophenyl)-3-methylcarbamyl-4methyl7,8-methylenedioxy-3,4-dihydro-5 $\mathrm{H}$-2,3-

benzodiazepine], respectively.

\section{Materials and Methods}

All experiments were approved by the ethical committee of the local authorities and were conducted according to the German legislation on animal care.

Animal models. Experiments were performed on 10 adult male Sprague Dawley rats, five each for the two glutamate receptor antagonists (body weight of NMDA group, $401 \pm 53$ g; body weight of AMPA group, $374 \pm 43 \mathrm{~g}$; mean $\pm \mathrm{SD}$ ). The animals were housed under conventional conditions, in temperature-controlled $\left(21 \pm 2^{\circ} \mathrm{C}\right)$ and humiditycontrolled $(55 \pm 10 \%)$ facilities. Water and food were allowed ad libitum. Initial anesthesia during animal preparation was performed by inhalation of $1.5 \%$ halothane in a 7:3 $\mathrm{N}_{2} \mathrm{O} / \mathrm{O}_{2}$ mixture. Both femoral veins and arteries were catheterized for drug administration, measurement of blood gases (Blood Gas System 288; Ciba Corning Diagnostics, Fernwald, Germany), and continuous monitoring of arterial blood pressure. The rats were tracheotomized and mechanically ventilated after paralysis with pancuronium bromide $\left(0.1 \mathrm{mg} \cdot \mathrm{kg}^{-1} \cdot \mathrm{h}^{-1}\right.$; Ratiopharm, Ulm,
Germany). Ventilation was adjusted to maintain an arterial $\mathrm{pCO}_{2}$ of $\sim 35$ $\mathrm{mmHg}$. Body temperature was measured with a rectal thermocouple and kept at $37.5^{\circ} \mathrm{C}$ with a warm water blanket. All measured physiological parameters, i.e., arterial blood pressure, heart rate, body temperature, and EEG, were digitized, transferred to a personal computer, and continuously monitored (DASYLab; Datalog, Mönchengladbach, Germany).

For functional activation studies, anesthesia was switched to $\alpha$-chloralose (bolus of $80 \mathrm{mg} / \mathrm{kg}$, followed by continuous infusion of 40 $\mathrm{mg} \cdot] \mathrm{kg}^{-1} \cdot \mathrm{h}^{-1}$, i.v.). This anesthetic allows studying the physiology of functional brain activation (Leniger-Follert and Hossmann, 1979; Bonvento et al., 1994) and preserves the cerebrovascular coupling (Ueki et al., 1992; Lindauer et al., 1993). In the ventilation gas mixture, $\mathrm{N}_{2} \mathrm{O}$ was replaced by $\mathrm{N}_{2}$ (Gyngell et al., 1996).

Nuclear magnetic resonance methods. All fMRI experiments were performed on a $7 \mathrm{~T} / 30 \mathrm{~cm}$ magnet interfaced to a BioSpec AVANCE electronics (Bruker Biospin, Ettlingen, Germany) and equipped with actively shielded gradient coils [20 cm inner diameter (ID); $200 \mathrm{mT} / \mathrm{m}$ ]. Spin excitation was accomplished by a homebuilt $12 \mathrm{~cm}$ ID Helmholtz receptive field coil, which was actively decoupled from a $2.4 \mathrm{~cm}$ ID receiveonly surface coil used for signal detection. Pilot stimulations served to locate the activation maximum in the contralateral somatosensory cortex, located at an average of $\sim 4.5 \mathrm{~mm}$ caudal of the rhinal fissure and 4 $\mathrm{mm}$ lateral to midline (Bock et al., 1998). A spin-echo echo-planar imaging (EPI) sequence, modified to allow the simultaneous acquisition of blood oxygenation level-dependent (BOLD)- and perfusion-weighted contrast (Silva and Kim, 1999) was used for all fMRI experiments. Arterial spin labeled (Williams et al., 1992) and control images were acquired in an interleaved manner. The control images were used to measure the relative BOLD changes induced by forepaw stimulation, whereas relative perfusion changes were obtained by a weighted subtraction of the labeled images from the control images (Williams et al., 1992). Imaging parameters were as follows: matrix size, $64 \times 32$; field of view, $2.56 \times 1.28 \mathrm{~cm}^{2}$; slice thickness, $2 \mathrm{~mm}$, for a nominal spatial resolution of $400 \times 400 \times$ $2000 \mu \mathrm{m}^{3}$. The echo time (TE) was set at $27 \mathrm{~ms}$, whereas the repetition time (TR), equal to the labeling time, was set at $3000 \mathrm{~ms}$. Continuous arterial spin labeling was performed by selectively inverting arterial spins $2 \mathrm{~cm}$ proximal to the imaging plane, using a longitudinal gradient strength of $10 \mathrm{mT} / \mathrm{m}$ and a $B_{1}$ field of $\sim 80 \mathrm{mG}$ (Silva and Kim, 1999). Control images were obtained by inverting the sign of the receptive field frequency offset used to label the arterial spins. The temporal resolution of BOLD and perfusion-weighted imaging (PWI) was $6 \mathrm{~s}$.

In addition to BOLD and PWI measurements, relative cerebral blood volume (CBV) changes were also measured in four of the five animals of the AMPA-R subgroup. This was done by an intravenous administration of an intravascular contrast agent consisting of ultra-small superparamagnetic iron oxide particles [iron concentration, $20 \mathrm{mg} / \mathrm{kg}$ body weight; particle size, 20-40 nm; ferumoxtran-10 (Sinerem; Guerbet, Paris, France)] (Mandeville et al., 1998). The same EPI sequence as described above was used for CBV measurements but without arterial spin labeling (matrix size, $64 \times 32$; field of view, $2.56 \times 1.28 \mathrm{~cm}^{2}$; TE, $27 \mathrm{~ms}$; TR, $3000 \mathrm{~ms}$; slice thickness, $2 \mathrm{~mm}$ ).

After application of the contrast agent, equilibration within the vascular system was allowed for 10-15 min before the next forepaw stimulation. Relative CBV changes were calculated as follows:

$$
\frac{\Delta \mathrm{CBV}(t)}{\mathrm{CBV}(0)}=\ln \frac{S_{\mathrm{CBV}}(t)}{S_{\mathrm{CBV}}(0)} / \ln \frac{S_{\mathrm{CBV}}(0)}{S_{\mathrm{CBV} \text { pre }}},
$$

where $S_{\mathrm{CBV}}(0)$ is the signal intensity without stimulation, $S_{\mathrm{CBV}}(t)$ is the signal intensity during stimulation, and $S_{\mathrm{CBV}}$ pre is the signal intensity before contrast agent application (Mandeville et al., 1998).

Stimulation protocol. Electrical forepaw stimulation (Stimulator STG 1004; Multi Channel Systems, Reutlingen, Germany) was applied via two subcutaneous needle electrodes at the palmar side of the wrist. The right forepaws of the animals were stimulated by rectangular constant current pulses $(1 \mathrm{~mA}, 0.3 \mathrm{~ms})$ with a frequency of $2 \mathrm{~Hz}$. This stimulation frequency was chosen to optimize both the SEP recordings as well as the fMRI signals, which are maximum at $\sim 1 \mathrm{~Hz}$ (Brinker et al., 1999) and 3 $\mathrm{Hz}$ (Ngai et al., 1999; Silva et al., 1999), respectively. This stimulation 
Table 1. Effects of MK-801 and GYKI-53655 on physiological variables

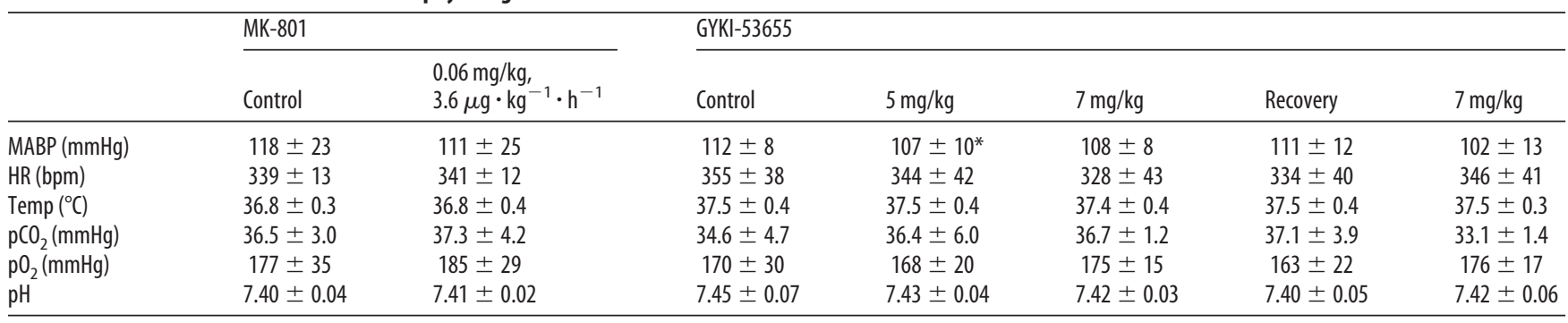

Values are expressed as means \pm SD ( $n=5$ animals per group). No significant difference was noted for any parameter except the mean arterial blood pressure after injection of $5 \mathrm{mg} / \mathrm{kg} \mathrm{GYKI}-53655$. ${ }^{*} p<0.05$ versus control. MABP, Mean arterial blood pressure; $H R$, heart rate; bpm, beats per minute; Temp, temperature.

frequency was also ideally suited for artifact-free recordings of the SEPs in the time gaps between the gradient switching phases of the applied fMRI sequence (Silva and Kim, 1999; Ogawa et al., 2000). The applied stimulus intensity of $1 \mathrm{~mA}$ produces painless stimulation (Gyngell et al., 1996; Bock et al., 1998), and the interstimulus interval with blocks of $30 \mathrm{~s}$ ON versus $90 \mathrm{~s}$ OFF stimulation was chosen to ensure absence of any significant habituation (Ances et al., 2000b).

Recording of somatosensory evoked potentials. The forepaw stimulation was triggered by the MR console so that stimuli were delivered in time windows between gradient switching to permit artifact-free SEP recordings (Ogawa et al., 2000). The ends of Teflon-insulated silver wires (10 $\mathrm{T} \times 25$ feet; Clark Electromedical Instruments, Reading, UK) were stripped and chlorided. Through a small occipital skin cut, the wires were advanced subcutaneously to reach the skull area above the somatosensory cortex. Thus, the skin above the somatosensory cortex remained intact, preventing susceptibility artifacts in the fMRI images. A reference electrode was placed on the nose, and the animals were grounded by an additional electrode in the neck. The EEG was amplified 1000-fold with a differential amplifier (B. Radermacher, Max-Planck-Institut for Neurological Research, Cologne, Germany) (impedance, $10^{12} \Omega$; commonmode rejection, $-120 \mathrm{db}$ ), hardware bandpass filtered between 0.5 and $1000 \mathrm{~Hz}$, transferred to a personal computer, and digitized with a sampling rate of $2 \mathrm{kHz}$. After digitization, the signals were bandpass filtered by software filters (DASYLab 5.6) between 1 and $100 \mathrm{~Hz}$. Hardware and software filters had Bessel characteristics. Averaging of 50 single recordings starting $50 \mathrm{~ms}$ before and ending $250 \mathrm{~ms}$ after a stimulus yielded one SEP. After data reduction, SEPs were stored on hard disk with a temporal resolution of $1 \mathrm{~ms}$. For quantification (Schwindt et al., 2004), we measured the amplitude and the latency of the first three peaks of the SEPs: P1, N1, and P2 (see Fig. 4).

Experimental protocol. Before the systemic administration of the receptor antagonists, 15 blocks of ON versus OFF stimulation periods were recorded, confirming stable BOLD and PWI responses during this 30 min period ( 15 blocks of $120 \mathrm{~s}$ ) (see Fig. 1). For assessing the effects of the glutamate receptor antagonists MK-801 and GYKI-53655, we recorded long series of stimulation blocks of 30 and $50 \mathrm{~min}$, respectively. The receptor antagonists were applied intravenously after the fifth block (10 min).

In pilot experiments, the noncompetitive, irreversibly binding NMDA-R antagonist MK-801 (Sigma-Aldrich, Deisenhofen, Germany) showed stable effects $10 \mathrm{~min}$ after application. We recorded a total of 15 stimulation blocks (30 min) after administration of a bolus of $60 \mu \mathrm{g} / \mathrm{kg}$, followed by a continuous infusion of $3.6 \mu \mathrm{g} \cdot \mathrm{kg}^{-1} \cdot \mathrm{hr}^{-1}$ intravenously (Nehls et al., 1990; Gill et al., 1991; Dawson et al., 1994).

Because of the reversible binding of the noncompetitive AMPA-R antagonist GYKI-53655 (Sigma-Aldrich), we recorded a total of 25 stimulation blocks (i.e., $50 \mathrm{~min}$ ) to additionally include the expected recovery phases. GYKI-53655 was dissolved in Ringer's solution with $10 \%(\mathrm{w} / \mathrm{w})$ cyclodextrine (Sigma-Aldrich) and applied in two dosages of 5 and 7 $\mathrm{mg} / \mathrm{kg}$ (Ruiz and Durand, 2000) to assess dose dependence. The second dose was given after a recovery period of $60 \mathrm{~min}$. After another hour $(2 \mathrm{~h}$ after the initial application), changes of CBV were measured after the application of the super-paramagnetic iron oxide contrast agent in resting conditions and after a third bolus of GYKI-53655 (7 mg/kg).

Image analysis. Image analysis was performed as described previously (Burke et al., 2000) using the software package Stimulate (Strupp, 1996).
After filtering the images with a Gaussian kernel, the statistical parametric maps were generated using a paired Student's $t$ test $(p \leq 0.05)$. The statistical significance for each cluster of activated pixels was calculated, and only clusters with a confidence level of $p \leq 0.05$ entered additional analyses (Xiong et al., 1995).

Clusters significantly activated in the BOLD data during the first five control stimulation blocks before the systemic injection of receptor antagonists were defined as regions of interest (ROIs) for the additional analyses (see Fig. $1 B$ ). These ROIs were also transferred to the PWI and $\mathrm{CBV}$ images for determining the drug effects on these parameters.

Data and statistical analysis. SEPs, as well as BOLD, PWI, and CBV changes, were normalized to the respective control phases (four stimulation blocks before the respective injection of the drugs) and expressed as means \pm SD. The action of GYKI-53655 on the mean signal amplitude changes was determined based on the five stimulation blocks immediately after the drug injection because this compound has a short and reversible action. For MK-801, we also averaged five blocks but used five blocks starting $10 \mathrm{~min}$ after drug injection to allow the effect of MK-801 to reach a steady state. The mean amplitude changes of BOLD and PWI before and after MK-801 application were tested for statistical significance using Student's paired $t$ test $(p<0.05)$. Differences of the BOLD, PWI, and CBV responses as well as between the respective control phases before GYKI- 53655 application were assessed by paired Student's $t$ tests. Effects of MK-801 and GYKI-53655 on the different SEP components were assessed by two-way repeated-measures ANOVA with Holm-Sidak post hoc tests $(p<0.05)$.

\section{Results}

\section{Control of animal physiology}

Animal physiology was carefully monitored and controlled throughout the whole extent of the experiments. As shown in Table 1, all physiological variables recorded during baseline, as well as after the application of either MK-801 or GYKI-53655, were within the normal range. At each dose, MK-801 and GYKI53655 induced small, transient decreases in blood pressure and heart rate during the first $30 \mathrm{~s}$ after administration. Thereafter, only after $5 \mathrm{mg} / \mathrm{kg}$ GYKI-53655 was blood pressure significantly reduced by $\sim 4 \%(p<0.05)$ (Table 1$)$. There were no other significant effects on any of the recorded physiological parameters (Table 1). Furthermore, there were no stimuli-evoked increases in blood pressure or heart rate, indicating the absence of systemic effects, in particular of pain.

\section{fMRI}

Under normal physiological conditions, electrical stimulation of the right forepaw induced a significant increase in BOLD (6 \pm $1 \%)$ and PWI $(101 \pm 22 \%)$ signals in the contralateral somatosensory cortex (Fig. 1). The chosen stimulation paradigm produced robust activation in primary somatosensory cortex (Fig. $1 A)$. The BOLD and PWI response was stable from block to block, and we observed no significant habituation for consecutive stimulation epochs, as shown in Figure $1 B$ (Ances et al., 2000a). 

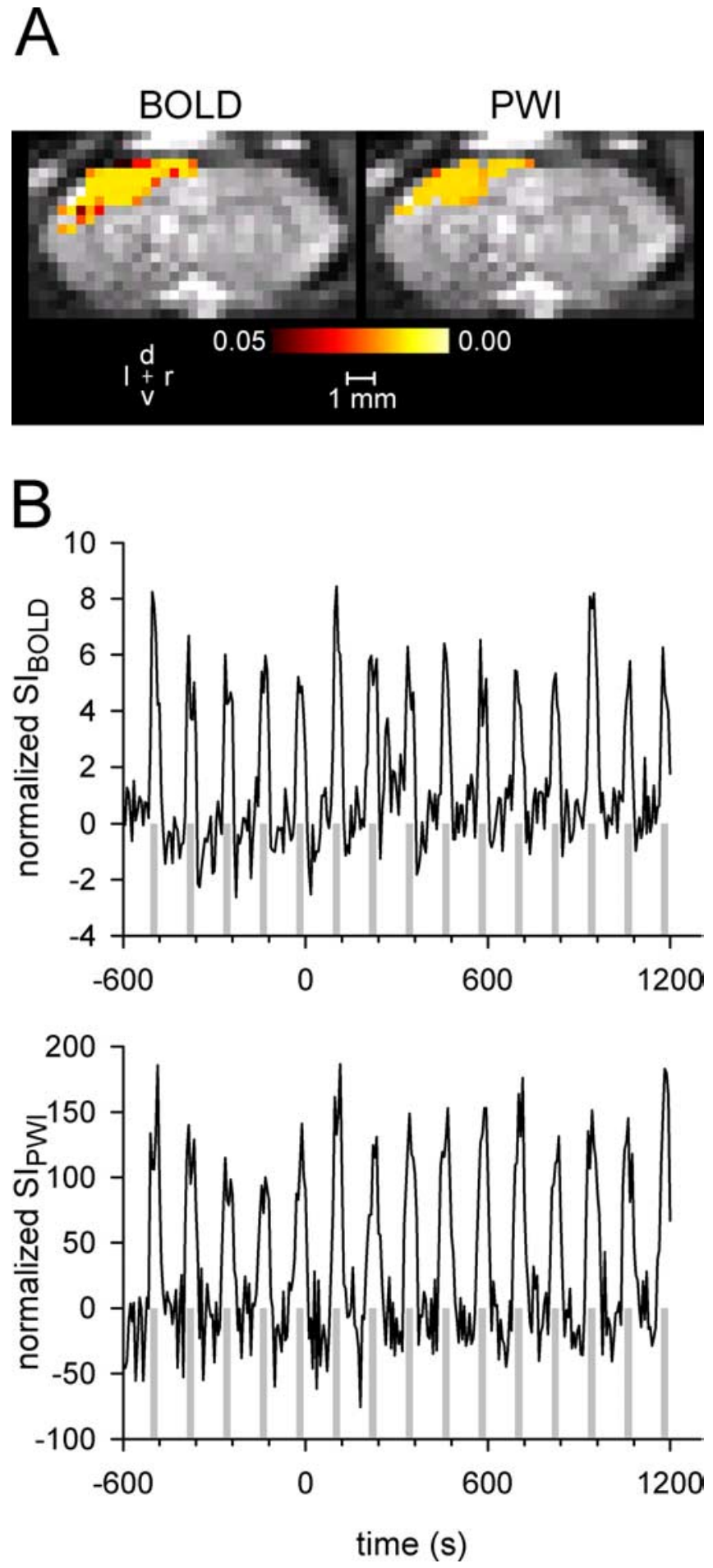

Figure 1. A, Representative activation maps calculated from BOLD and PWI signals after electrical forepaw stimulation. Forepaw stimulation produced robust and localized hemodynamic changes over primary somatosensory cortex. The color bar indicates the statistical level of significance. $\boldsymbol{B}$, Time courses of BOLD and PWI signal intensity changes in the control situation without drug application normalized to the baseline signal intensity between the first five stimulation blocks. Stable and robust signal changes were obtained at every stimulus epoch. Stimulation blocks are indicated by the gray bars.

Figure $2 A$ shows typical BOLD (top row) and PWI (bottom row) signal intensity time courses before and after administration of MK-801 (left) and GYKI-53655 (right), normalized to the baseline between the four stimulation blocks preceding the appli-
A
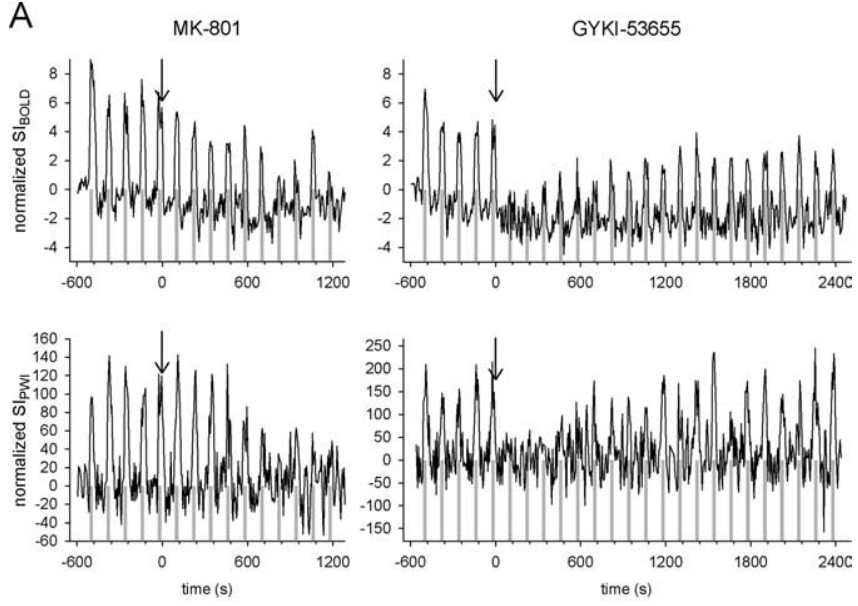

B
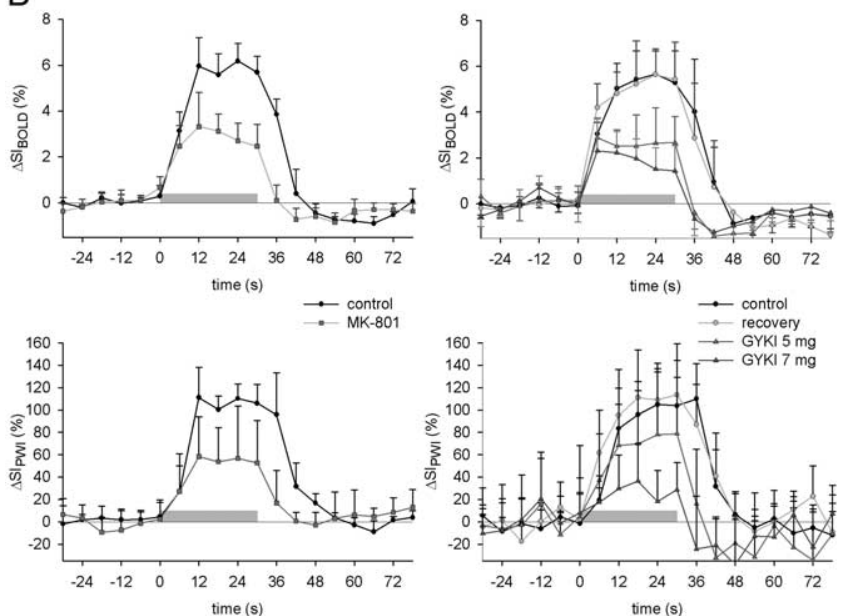

Figure 2. A, Typical time courses of BOLD (top row) and PWI (bottom row) percentage signal changes after administration of MK-801 (left) and GYKI-53655 (right), normalized to the baseline between the four stimulation blocks preceding the application of glutamate antagonists. Administration of the NMDA-R antagonist (left) after the fifth stimulation epoch (arrows) produced a delayed yet irreversible reduction in the BOLD and PWI responses to stimulation. Conversely, administration of the AMPA-R antagonist (right, arrows) produced immediate and significant reduction in BOLD and PWI signals, but such reduction was reversed within 30 min of administration. Stimulation blocks are marked by gray bars. $B$, Average time courses of BOLD (top row) and PWI (bottom row) percentage signal changes after administration of MK-801 (left) and GYKI-53655 (right). MK-801 produced a strong reduction of BOLD ( $-51 \%)$ and PWI $(-57 \%)$ responses. Administration of the AMPA-R antagonist, conversely, produced dosedependent reductions in BOLD ( -49 and $-68 \%)$ and PWI $(-22$ and $-68 \%)$ after 5 and 7 $\mathrm{mg} / \mathrm{kg}$, respectively, which completely recovered within $30 \mathrm{~min}$ of administration. Error bars indicate 1 SD.

cation of the glutamate antagonists. Administration of MK-801, the NMDA-R antagonist, produced a delayed yet irreversible reduction in the BOLD and PWI response to stimulation. Conversely, administration of GYKI-53655, the AMPA-R antagonist, produced an immediate and significant reduction in BOLD and PWI signals, which recovered within $30 \mathrm{~min}$ of administration of GYKI-53655. Figure $2 B$ shows BOLD (top row) and PWI (bottom row) time courses averaged across all animals and across five stimulation blocks before and after application of MK-801 (left) and GYKI-53655 (right). MK-801 caused robust and irreversible decreases in the BOLD $(-51 \pm 19 \%)$ and PWI $(-57 \pm 26 \%)$ responses to somatosensory stimulation when compared with the control period. GYKI-53655, conversely, decreased the BOLD and PWI responses in a dose-dependent yet reversible manner (BOLD, $-49 \pm 13$ and $-65 \pm 15 \%$; PWI, $-22 \pm 48$ and 


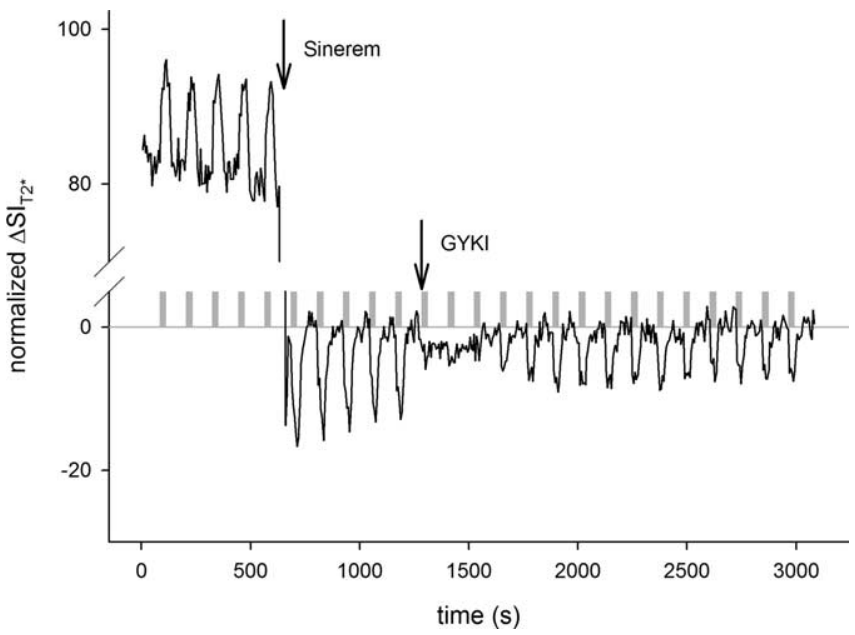

Figure 3. Time course of $\mathrm{T}_{2}{ }^{*}$-weighted MRI signal intensity before (first 5 blocks) and after (arrow) intravenous administration of Sinerem, an ultra-small super-paramagnetic iron oxide particles intravascular contrast agent. The blood pool contrast agent causes a general signal decrease in $\mathrm{T}_{2}{ }^{*}$-weighted images because of increased susceptibility differences. Note that the initially positive signal changes (BOLD) become negative after Sinerem because the susceptibility differences are augmented by the stimulation-induced CBV increases. Five stimulus epochs after Sinerem, GYKI-53655 was administered (2nd arrow), causing an immediate decrease in the CBV-weighted signal that recovered partially after approximately six blocks.

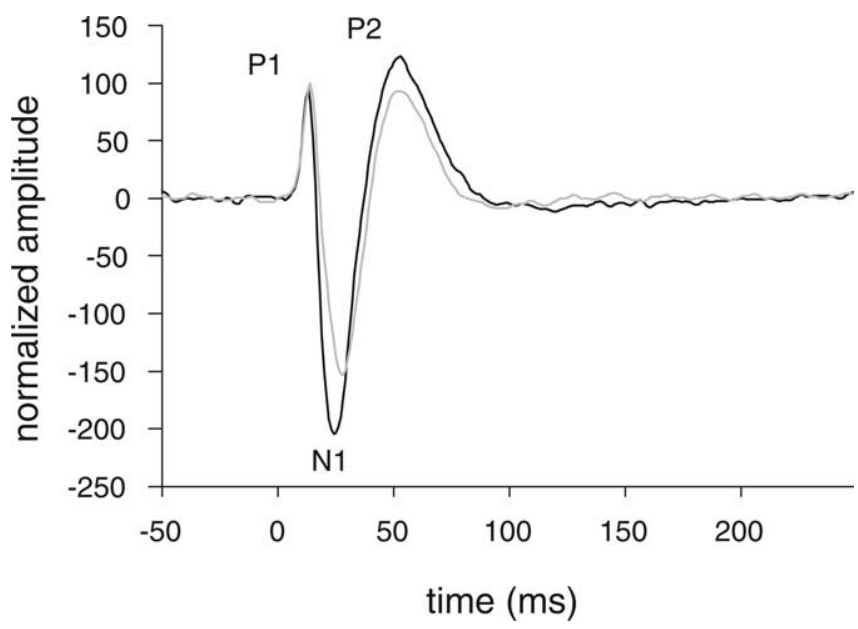

Figure 4. Representative SEPs in the control phase (black curve) and after MK-801 application (gray curve), identifying the three major components of the SEP: the P1, N1, and P2 peaks.

$-68 \pm 4 \%$ for 5 and $7 \mathrm{mg} / \mathrm{kg}$, respectively). As shown in Figures $2, A$ and $B$, and 5 , recovery was complete. There were no significant differences between the different control periods of the respective GYKI-53655 applications.

Figure 3 shows the time course of $\mathrm{T}_{2}{ }^{*}$-weighted MRI signal intensity before (first five blocks) and after (arrow) intravenous administration of Sinerem, an intravascular MRI contrast agent consisting of ultra-small super-paramagnetic iron oxide particles (for explanation, see figure legend). The CBV response was strongly attenuated after the administration of $7 \mathrm{mg} / \mathrm{kg}$ GYKI53655. It decreased from $14.0 \pm 4.9 \%$ (control) to $2.9 \pm 1.6 \%$, i.e., by $80 \pm 11 \%(p<0.001)$ compared with control.

\section{Electrophysiological recordings}

Figure 4 shows typical SEP recordings during normal forepaw stimulation. Excellent signal-to-noise ratio was obtained from such recordings, performed inside the magnet, which allowed us

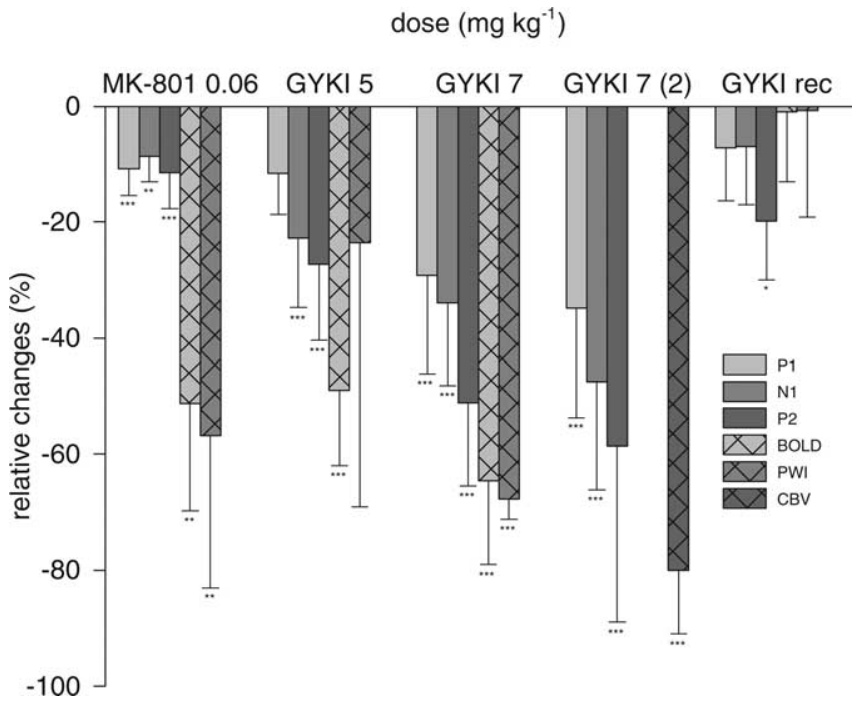

Figure 5. Summary of the reduction in amplitude of the individual SEP components and the BOLD and PWI responses attributable to administration of MK- 801 and GYKI-53655. Values are expressed in percentage signal decrease (mean $\pm S D$ ) relative to the control situation (average of 5 stimulation blocks before the injection of drugs). MK-801 produced a small (approximately $-10 \%)$, uniform yet significant decrease in amplitude of all three SEP components $(p<0.01)$ but produced robust (approximately $-52 \%$ ) and irreversible decreases in the BOLD and PWI responses ( $p<0.01$, paired $t$ test); the SEP reduction was significantly smaller than the reduction of the BOLD and PWI response $(p<0.001)$. GYKI-53655 produced robust, dose-dependent yet reversible decreases in both the SEP amplitudes and the hemodynamic responses to stimulation. Unless stated otherwise, repeated-measures two-way ANOVA with Holm-Sidak post hoc test was used. ${ }^{*} p<0.05,{ }^{* *} p<0.01,{ }^{* * *} p<0.001$ compared with control.

to reliably identify and delineate the three major SEP components, $\mathrm{P} 1, \mathrm{~N} 1$, and $\mathrm{P} 2$, at latencies of $14 \pm 1,24 \pm 2$, and $50 \pm 4$ $\mathrm{ms}$, respectively (Fig. 4). Unlike the hemodynamic results obtained with fMRI, administration of GYKI-53655 and MK-801 had substantially different effects on the SEPs. MK-801 diminished all SEP amplitudes, P1, N1, and P2, but only by 10\% (Fig. 5 , main effect for MK-801 treatment, $p<0.05$ ) (for post hoc results of the individual SEP components, see Fig. 5) compared with 50\% decrease $(p<0.001)$ in the hemodynamic response. There were no significant latency changes (data not shown). Conversely, application of GYKI-53655 induced a marked decrease in amplitude of all three components in a dose-dependent manner, with a range of $15-35 \%$ for $\mathrm{P} 1,25-50 \%$ for $\mathrm{N} 1$, and $30-60 \%$ for P2 (Fig. 5, main effect for 5 and $7 \mathrm{mg}$ of GYKI-53655 vs control, $p<0.001$; not significant for control vs recovery; 5 vs $7 \mathrm{mg}$ of GYKI-53655, $p<0.05$ ) (for post hoc results for the individual SEP components vs control, see Fig. 5). Such substantial reduction matched well the reduction in the hemodynamic response observed with $\mathrm{fMRI}$. The latency of P1 was only slightly increased in the millisecond range after GYKI-53655 and was not significantly changed for N1 and P2.

\section{Kinetics of decay and recovery of SEP and hemodynamic response}

The time courses of the MRI parameters (Fig. 2A) and of the SEP amplitudes after drug treatment were used to determine the decay and recovery time constants of the respective signals. For MK-801, the decay time constant was measured as the time point after application of the drug at which the relative BOLD, PWI, or SEP amplitude reached $50 \%$ of its full reduction at steady state. For GYKI-53655, the decay and recovery time constants were measured as the time point after application of the drug at which 
the relative BOLD, PWI, or SEP amplitude reached $50 \%$ of its maximum effect and the time point from the maximum effect to maximum recovery, respectively. Table 2 summarizes the results of the kinetic analysis, which were entirely different for MK801 and GYKI-53655. MK-801 had a significantly longer decay time constant (8-12 $\mathrm{min}$ for BOLD and PWI; 14-16 $\mathrm{min}$ for SEP) when compared with GYKI-53655 (instantaneous, $<2 \mathrm{~min}$ ). The recovery time constants for GYKI-53655 ranged between 20 and 30 min but were similar for SEPs and fMRI parameters and did not show significant dose-dependent differences.

\section{Discussion}

Our data indicate that the interaction of glutamate with its postsynaptic and/or glial receptors is necessary for the production of blood flow and BOLD responses. Excitatory glutamatergic synapses dominate in the brain so that both glutamate metabolism and the consequences of glutamate release are the main energy-consuming processes in the working brain (Attwell and Iadecola, 2002). Indeed, it has been shown previously that antagonists of glutamate receptors attenuate both synaptic (extracellular local field potentials) and blood flow responses (laser-Doppler flowmetry) mainly in the cerebellum (for references, see Lauritzen, 2005) but also in the somatosensory cortex (Nielsen and Lauritzen, 2001). The role of the glutamatergic system for the generation of fMRI signals has indirectly been studied after lamotrigine, which indirectly inhibits glutamate release through blocking presynaptic voltage-gated $\mathrm{Na}^{+}$and $\mathrm{Ca}^{2+}$ channels, thus leading to an unspecific inhibition of glutamate release (Kida et al., 2001; Kida et al., 2006). Our study not only confirms these results by directly recording BOLD and PWI signals but allows differentiating between the major ionotropic glutamate receptors.

NMDA and non-NMDA receptors contribute to natural processing of somatosensory information within the rat somatosensory cortex (Armstrong-James et al., 1993). Very fast thalamocortical transmission to layer IV (5-8 ms after stimulus), commensurate to monosynaptic relay for layer IV cells, is almost entirely mediated by non-NMDA-Rs. The fast $(10 \mathrm{~ms})$ and slower (until $100 \mathrm{~ms}$ ) transmissions to layers I-IV mainly depend on NMDA-Rs, and NMDA-Rs are also involved in intracortical signal transmission (Hess et al., 1994). The main results of this study are the differential effects of these two ionotropic glutamate receptors on the BOLD and PWI responses as measured by fMRI and on the neuronal activity as measured by SEPs during functional somatosensory stimulation of the rat forepaw. As summarized in Figure 5, the NMDA-R antagonist MK-801 only slightly diminished the amplitudes of the three major components of the SEPs but markedly reduced both BOLD and PWI responses. In contrast, the AMPA-R antagonist GYKI-53655 strongly and dose dependently decreased both hemodynamic/metabolic and electrophysiological responses. The differences observed in the time course of both drugs likely reflect their pharmacokinetics (Gill et al., 1991; Ruiz and Durand, 2000).

\section{NMDA-type glutamate receptors}

The first positive component P1 (mean latencies of $14 \mathrm{~ms}$ ) is supposed to reflect mainly the activity of the thalamocortical pathway (Tokuno et al., 1992), whereas the other components N1 (24 ms) and P2 (50 ms) are probably generated later in the cortex (Peterson et al., 1995). NMDA-Rs are involved in both fast (10 $\mathrm{ms}$ ) and slow (until $100 \mathrm{~ms}$ ) transmissions to layers I-IV so that their contribution should be observed in all three components, including P1. Another explanation for the reduction of the early SEP components might be that corticothalamic feedback suppresses the activity of thalamocortical afferents (Ahissar et al., 2000; Chung et al., 2002). We indeed observed a rather uniform decrease of the different components of the SEPs as shown previously in the somatosensory cortex (Kvajo et al., 2004). However, such uniform decrease did not allow the localization of a predominant site of action for the NMDA-R antagonist.

Because the decay of the CBF response does not precede the SEP reduction, it is likely that the latter directly reflected the reduction of NMDA-R-mediated postsynaptic currents. The applied dosage was chosen to prevent sustained or physiologically significant changes in blood pressure and heart rate (Gill et al., 1991). It is therefore unlikely that the decreased flow response to forepaw stimulation observed under NMDA-R blockade was the consequence of an impairment of autoregulation (Paulson et al., 1990). Studies performed on isolated cerebral microvessels have shown that glutamate is devoid of vasoactive effects on isolated arteries studied in vitro and that there are no glutamatergic receptors on the vasculature (Morley et al., 1998). However, it has long been proposed that NMDA-Rs can exert an indirect vasomotor role via the release of nitric oxide (NO) (Garthwaite et al., 1988; Faraci and Breese, 1993). The neuronal isoform of NO synthase (nNOS) cleaves NO from L-arginine in a $\mathrm{Ca}^{2+}$-dependent reaction and is physically anchored to the $\mathrm{Ca}^{2+}$-permeable NMDA-R by two postsynaptic density proteins, PSD-93 and PSD-95 (Brenman et al., 1996a,b). Such a hypothesis (of NO mediation) is supported by our recent observation that administration of 7-nitroindazole (7-NI), a specific blocker of the nNOS, mildly reduced the SEPs components, whereas both PWI and BOLD responses were strongly reduced (Burke et al., 2002). These results are also consistent with the numerous studies reporting that 7-NI significantly reduces the CBF response to whisker stimulation in the somatosensory cortex in both awake (Gotoh et al., 2001) and anesthetized (Cholet et al., 1997) rats.

NMDA receptors appear thus to be an essential part of the signaling chain generating the BOLD and PWI responses after neuronal activation, at least in the somatosensory cortex. 


\section{AMPA-type glutamate receptors}

The AMPA-R antagonist GYKI-53655 reduced all SEP amplitudes and concurrently decreased the BOLD and PWI responses in a dose-dependent manner. The observed attenuation of SEP amplitudes may be explained considering AMPA-R expression and their functional relevance in the somatosensory system. A considerable fraction of afferent neurotransmission is mediated by AMPA-R on the thalamic (Schwarz and Block, 1994) as well as on the cortical (Armstrong-James et al., 1993) level. Accordingly, AMPA-Rs are expressed in the ventrolateral posterior nucleus and the reticular nucleus of the thalamus (Liu, 1997; Ozawa et al., 1998; Mineff and Weinberg, 2000), as well as in the somatosensory cortex (Palomero-Gallagher and Zilles, 2004). It follows that any global blockade of AMPA-R will disrupt the thalamocortical input so that all neural responses (fast and slow) will be decreased in the somatosensory cortex. We indeed obtained a marked decrease of all components (P1, N1, and P2) after intravenous injection of GYKI-53655 in vivo.

In contrast to MK-801, in which SEPs were only mildly reduced compared with the pronounced reduction of the BOLD/ PWI responses, the reduced electrophysiological and fMRI responses were of similar extent after GYKI-53655, suggesting a preserved coupling between neuronal activity and the hemodynamic response. As for the NMDA-Rs, no AMPA-Rs are found on the vasculature (Morley et al., 1998) so that indirect mechanisms should link AMPA-R-mediated neurotransmission and fMRI responses. Although such a signaling pathway has not yet been described, it is likely that it involves phasic changes in intracellular calcium and glia. Such changes are known to activate enzymes responsible for the production of vasodilating compounds such as NO, prostaglandins, and epoxyeicosatrienoic acids (for references, see Lauritzen, 2005). Another possibility would be that AMPA-R blockade indirectly inhibited NMDA-Rmediated neurotransmission and subsequently the NMDA-Rmediated cerebrovascular response as described above. AMPA-Rs and NMDA-Rs are frequently colocalized in central postsynaptic membranes (Kharazia et al., 1996; Takumi et al., 1999) and in the thalamus (Liu, 1997). One unique feature of the NMDA-Rs compared with other ligand-gated ion channels is the dual dependence of function on agonist binding and membrane potential. At resting potential, NMDA-Rs are efficiently blocked by the $\mathrm{Ca}^{2+}$ analog $\mathrm{Mg}^{2+}$, so that a depolarization of the postsynaptic membrane is essentially required for NMDA-R-mediated channel opening and $\mathrm{Ca}^{2+}$ influx (Nowak et al., 1984; Ozawa et al., 1998; Ziff, 1999). An insufficient membrane depolarization resulting from AMPA-R blockade could thus indirectly inhibit NMDA-R opening.

\section{Conclusion}

Our study clearly showed the substantial but differential contribution of the two major ionotropic glutamate receptors for the occurrence of both electrical and hemodynamic responses during somatosensory stimulation. The proposed mechanisms likely represent only part of the far more complex interplay, coupling neuronal activity to the hemodynamic response. The remaining electrical and hemodynamic responses after glutamate receptor antagonist application may result from incomplete receptor blocking or could be linked to glutamate-independent mechanisms (e.g., other transmitter systems such as GABA) (Caesar et al., 2003) or may involve additional potential mediators such as adenosine, potassium, or others. Finally, these results should be taken into account in experimental conditions in which the glutamatergic system is affected, as during pathology such as migraine, peritumoral tissue, ischemia, or neurodegenerative disorders.

\section{References}

Ahissar E, Sosnik R, Haidarliu S (2000) Transformation from temporal to rate coding in a somatosensory thalamocortical pathway. Nature 406:302-306.

Ances BM, Greenberg JH, Detre JA (2000a) Effects of variations in interstimulus interval on activation-flow coupling response and somatosensory evoked potentials with forepaw stimulation in the rat. J Cereb Blood Flow Metab 20:290-297.

Ances BM, Zarahn E, Greenberg JH, Detre JA (2000b) Coupling of neural activation to blood flow in the somatosensory cortex of rats is time-intensity separable, but not linear. J Cereb Blood Flow Metab 20:921-930.

Armstrong-James M, Welker E, Callahan CA (1993) The contribution of NMDA and non-NMDA receptors to fast and slow transmission of sensory information in the rat SI barrel cortex. J Neurosci 13:2149-2160.

Attwell D, Iadecola C (2002) The neural basis of functional brain imaging signals. Trends Neurosci 25:621-625.

Attwell D, Laughlin SB (2001) An energy budget for signaling in the grey matter of the brain. J Cereb Blood Flow Metab 21:1133-1145.

Bernardinelli Y, Magistretti PJ, Chatton JY (2004) Astrocytes generate $\mathrm{Na}^{+}$. mediated metabolic waves. Proc Natl Acad Sci USA 101:14937-14942.

Bock C, Krep H, Brinker G, Hoehn-Berlage M (1998) Brainmapping of alpha-chloralose anesthetized rats with $\mathrm{T} 2{ }^{\star}$-weighted imaging: distinction between the representation of the forepaw and hindpaw in the somatosensory cortex. NMR Biomed 11:115-119.

Bonvento G, Charbonne R, Correze JL, Borredon J, Seylaz J, Lacombe P (1994) Is alpha-chloralose plus halothane induction a suitable anesthetic regimen for cerebrovascular research. Brain Res 665:213-221.

Bonvento G, Sibson N, Pellerin L (2002) Does glutamate image your thoughts? Trends Neurosci 25:359-364.

Brenman JE, Christopherson KS, Craven SE, McGee AW, Bredt DS (1996a) Cloning and characterization of postsynaptic density 93, a nitric oxide synthase interacting protein. J Neurosci 16:7407-7415.

Brenman JE, Chao DS, Gee SH, McGee AW, Craven SE, Santillano DR, Wu Z, Huang F, Xia H, Peters MF, Froehner SC, Bredt DS (1996b) Interaction of nitric oxide synthase with the postsynaptic density protein PSD-95 and alpha1-syntrophin mediated by PDZ domains. Cell 84:757-767.

Brinker G, Bock C, Busch E, Krep H, Hossmann KA, Hoehn-Berlage M (1999) Simultaneous recording of evoked potentials and $T^{\star}(2)$-weighted MR images during somatosensory stimulation of rat. Magn Reson Med 41:469-473.

Burke M, Schwindt W, Ludwig U, Hennig J, Hoehn M (2000) Facilitation of electric forepaw stimulation-induced somatosensory activation in rats by additional acoustic stimulation: an fMRI investigation. Magn Reson Med 44:317-321.

Burke M, Schwindt W, Silva AC, Koretsky AP, Hoehn M (2002) Does BOLD reflect neuronal activity? Uncoupling of the hemodynamic response by inhibition of the neuronal NO-synthetase. Proceedings of the 10th Scientific Meeting of the International Society of Magnetic Resonance In Medicine, Honolulu, Hawaii, May.

Caesar K, Gold L, Lauritzen M (2003) Context sensitivity of activitydependent increases in cerebral blood flow. Proc Natl Acad Sci USA 100:4239-4244.

Chatton JY, Marquet P, Magistretti PJ (2000) A quantitative analysis of L-glutamate-regulated $\mathrm{Na}^{+}$dynamics in mouse cortical astrocytes: implications for cellular bioenergetics. Eur J Neurosci 12:3843-3853.

Cholet N, Seylaz J, Lacombe P, Bonvento G (1997) Local uncoupling of the cerebrovascular and metabolic responses to somatosensory stimulation after neuronal nitric oxide synthase inhibition. J Cereb Blood Flow Metab 17:1191-1201.

Chung S, Li X, Nelson SB (2002) Short-term depression at thalamocortical synapses contributes to rapid adaptation of cortical sensory responses in vivo. Neuron 34:437-446.

Dawson DA, Graham DI, McCulloch J, Macrae IM (1994) Anti-ischaemic efficacy of a nitric oxide synthase inhibitor and a $N$-methyl-D-aspartate receptor antagonist in models of transient and permanent focal cerebral ischaemia. Br J Pharmacol 113:247-253.

De Felipe J, Marco P, Fairen A, Jones EG (1997) Inhibitory synaptogenesis in mouse somatosensory cortex. Cereb Cortex 7:619-634.

Faraci FM, Breese KR (1993) Nitric oxide mediates vasodilatation in response to activation of $N$-methyl-D-aspartate receptors in brain. Circ Res 72:476-480.

Garthwaite J, Charles SL, Chess-Williams R (1988) Endothelium-derived 
relaxing factor release on activation of NMDA receptors suggests role as intercellular messenger in the brain. Nature 336:385-388.

Gill R, Brazell C, Woodruff GN, Kemp JA (1991) The neuroprotective action of dizocilpine (MK-801) in the rat middle cerebral artery occlusion model of focal ischaemia. Br J Pharmacol 103:2030-2036.

Gotoh J, Kuang TY, Nakao Y, Cohen DM, Melzer P, Itoh Y, Pak H, Pettigrew K, Sokoloff L (2001) Regional differences in mechanisms of cerebral circulatory response to neuronal activation. Am J Physiol Heart Circ Physiol 280:H821-H829.

Gyngell ML, Bock C, Schmitz B, Hoehn-Berlage M, Hossmann KA (1996) Variation of functional MRI signal in response to frequency of somatosensory stimulation in alpha-chloralose anesthetized rats. Magn Reson Med 36:13-15.

Herard AS, Dubois A, Escartin C, Tanaka K, Delzescaux T, Hantraye P, Bonvento G (2005) Decreased metabolic response to visual stimulation in the superior colliculus of mice lacking the glial glutamate transporter GLT-1. Eur J Neurosci 22:1807-1811.

Hess G, Jacobs KM, Donoghue JP (1994) N-methyl-D-aspartate receptor mediated component of field potentials evoked in horizontal pathways of rat motor cortex. Neuroscience 61:225-235.

Iadecola C (2004) Neurovascular regulation in the normal brain and in Alzheimer's disease. Nat Rev Neurosci 5:347-360.

Kharazia VN, Phend KD, Rustioni A, Weinberg RJ (1996) EM colocalization of AMPA and NMDA receptor subunits at synapses in rat cerebral cortex. Neurosci Lett 210:37-40.

Kida I, Hyder F, Behar KL (2001) Inhibition of voltage-dependent sodium channels suppresses the functional magnetic resonance imaging response to forepaw somatosensory activation in the rodent. J Cereb Blood Flow Metab 21:585-591.

Kida I, Smith AJ, Blumenfeld H, Behar KL, Hyder F (2006) Lamotrigine suppresses neurophysiological responses to somatosensory stimulation in the rodent. NeuroImage 29:216-224.

Kvajo M, Albrecht H, Meins M, Hengst U, Troncoso E, Lefort S, Kiss JZ, Petersen CC, Monard D (2004) Regulation of brain proteolytic activity is necessary for the in vivo function of NMDA receptors. J Neurosci 24:9734-9743.

Lauritzen M (2005) Reading vascular changes in brain imaging: is dendritic calcium the key? Nat Rev Neurosci 6:77-85.

Lauritzen M, Gold L (2003) Brain function and neurophysiological correlates of signals used in functional neuroimaging. J Neurosci 23:3972-3980.

Leniger-Follert E, Hossmann K-A (1979) Simultaneous measurement of microflow and evoked potentials in the somatomotor cortex of the cat brain during specific sensory activation. Pflügers Arch 380:85-89.

Lindauer U, Villringer A, Dirnagl U (1993) Characterization of CBF response to somatosensory stimulation: model and influence of anesthetics. Am J Physiol 264:H1223-H1228.

Liu XB (1997) Subcellular distribution of AMPA and NMDA receptor subunit immunoreactivity in ventral posterior and reticular nuclei of rat and cat thalamus. J Comp Neurol 388:587-602.

Logothetis NK, Pfeuffer J (2004) On the nature of the BOLD fMRI contrast mechanism. Magn Reson Imaging 22:1517-1531.

Logothetis NK, Wandell BA (2004) Interpreting the BOLD signal. Annu Rev Physiol 66:735-769.

Mandeville JB, Marota JJ, Kosofsky BE, Keltner JR, Weissleder R, Rosen BR, Weisskoff RM (1998) Dynamic functional imaging of relative cerebral blood volume during rat forepaw stimulation. Magn Reson Med 39:615-624.

Mineff EM, Weinberg RJ (2000) Differential synaptic distribution of AMPA receptor subunits in the ventral posterior and reticular thalamic nuclei of the rat. Neuroscience 101:969-982.

Morley P, Small DL, Murray CL, Mealing GA, Poulter MO, Durkin JP, Stanimirovic DB (1998) Evidence that functional glutamate receptors are not expressed on rat or human cerebromicrovascular endothelial cells. J Cereb Blood Flow Metab 18:396-406.

Nehls DG, Park CK, MacCormack AG, McCulloch J (1990) The effects of $\mathrm{N}$-methyl-D-aspartate receptor blockade with MK-801 upon the relationship between cerebral blood flow and glucose utilisation. Brain Res 511:271-279.

Ngai AC, Jolley MA, D’Ambrosio R, Meno JR, Winn HR (1999) Frequencydependent changes in cerebral blood flow and evoked potentials during somatosensory stimulation in the rat. Brain Res 837:221-228.
Nicholls D (1992) A bioenergetic approach to the nerve terminal. Biochim Biophys Acta 1101:264-265.

Nielsen AN, Lauritzen M (2001) Coupling and uncoupling of activitydependent increases of neuronal activity and blood flow in rat somatosensory cortex. J Physiol (Lond) 533:773-785.

Nowak L, Bregestovski P, Ascher P, Herbet A, Prochiantz A (1984) Magnesium gates glutamate-activated channels in mouse central neurones. Nature 307:462-465.

Ogawa S, Lee TM, Stepnoski R, Chen W, Zhuo XH, Ugurbil K (2000) An approach to probe some neural systems interaction by functional MRI at neural time scale down to milliseconds. Proc Natl Acad Sci USA 97:11026-11031.

Ozawa S, Kamiya H, Tsuzuki K (1998) Glutamate receptors in the mammalian central nervous system. Prog Neurobiol 54:581-618.

Palomero-Gallagher N, Zilles K (2004) Isocortex. In: The rat nervous system, Ed 3 (Paxinos G, ed), p 659. San Diego: Academic.

Paulson OB, Strandgaard S, Edvinsson L (1990) Cerebral autoregulation. Cerebrovasc Brain Metab Rev 2:161-192.

Pellerin L, Magistretti PJ (1994) Glutamate uptake into astrocytes stimulates aerobic glycolysis: a mechanism coupling neuronal activity to glucose utilization. Proc Natl Acad Sci USA 91:10625-10629.

Peterson NN, Schroeder CE, Arezzo JC (1995) Neural generators of early cortical somatosensory evoked potentials in the awake monkey. Electroencephalogr Clin Neurophysiol 96:248-260.

Raichle ME (1998) Behind the scenes of functional brain imaging: a historical and physiological perspective. Proc Natl Acad Sci USA 95:765-772.

Rothman DL, Behar KL, Hyder F, Shulman RG (2003) In vivo NMR studies of the glutamate neurotransmitter flux and neuroenergetics: implications for brain function. Annu Rev Physiol 65:401-427.

Ruiz A, Durand J (2000) Blocking the trigeminal EPSP in rat abducens motoneurons in vivo with the AMPA antagonists NBQX and GYKI 53655. Brain Res Bull 52:99-107.

Schwarz M, Block F (1994) Visual and somatosensory evoked potentials are mediated by excitatory amino acid receptors in the thalamus. Electroencephalogr Clin Neurophysiol 91:392-398.

Schwindt W, Burke M, Pillekamp F, Luhmann HJ, Hoehn M (2004) Functional magnetic resonance imaging and somatosensory evoked potentials in rats with a neonatally induced freeze lesion of the somatosensory cortex. J Cereb Blood Flow Metab 24:1409-1418.

Siesjo BK (1978) Brain energy metabolism. New York: Wiley.

Silva AC, Kim SG (1999) Pseudo-continuous arterial spin labeling technique for measuring CBF dynamics with high temporal resolution. Magn Reson Med 42:425-429.

Silva AC, Lee SP, Yang G, Iadecola C, Kim SG (1999) Simultaneous blood oxygenation level-dependent and cerebral blood flow functional magnetic resonance imaging during forepaw stimulation in the rat. J Cereb Blood Flow Metab 19:871-879.

Strupp JP (1996) Stimulate. NeuroImage 3:S607.

Takumi Y, Matsubara A, Rinvik E, Ottersen OP (1999) The arrangement of glutamate receptors in excitatory synapses. Ann NY Acad Sci 868:474-482.

Tokuno T, Kataoka K, Asai T, Chichibu S, Kuroda R, Ioku M, Yamada K, Hayakawa T (1992) Functional changes in thalamic relay neurons after focal cerebral infarct: a study of unit recordings from VPL neurons after MCA occlusion in rats. J Cereb Blood Flow Metab 12:954-961.

Ueki M, Mies G, Hossmann K-A (1992) Effect of alpha-chloralose, halothane, pentobarbital and nitrous oxide anesthesia on metabolic coupling in somatosensory cortex of rat. Acta Anaesthesiol Scand 36:318-322.

Voutsinos-Porche B, Knott G, Tanaka K, Quairiaux C, Welker E, Bonvento G (2003a) Glial glutamate transporters and maturation of the mouse somatosensory cortex. Cereb Cortex 13:1110-1121.

Voutsinos-Porche B, Bonvento G, Tanaka K, Steiner P, Welker E, Chatton JY, Magistretti PJ, Pellerin L (2003b) Glial glutamate transporters mediate a functional metabolic crosstalk between neurons and astrocytes in the mouse developing cortex. Neuron 37:275-286.

Williams DS, Detre JA, Leigh JS, Koretsky AP (1992) Magnetic resonance imaging of perfusion using spin inversion of arterial water. Proc Natl Acad Sci USA 89:212-216.

Xiong J, Gao J-H, Lancaster JL, Fox PT (1995) Clustered pixels analysis for functional MRI activation studies of the human brain. Hum Brain Mapp 3:287-301.

Ziff EB (1999) Recent excitement in the ionotropic glutamate receptor field. Ann NY Acad Sci 868:465-473. 